\title{
Reform on MCU Course of College Based on PROTEUS Platform
}

\author{
Hong He and Jin-Zhou ZHANG \\ Tianjin Key Laboratory for Control Theory and \\ Application in Complicated Systems \\ Tianjin University of Technology \\ Heho604300@126.com
}

\author{
Lian LI and Hong-Jun WANG \\ Tianjin Key Laboratory for Control Theory and \\ Application in Complicated System \\ Tianjin University of Technology
}

\begin{abstract}
The measures and proposals of teaching reform in the MCU course based on PROTEUS platform are introduced in this paper. The reform of theoretical teaching and practical teaching is presented. At present, many colleges teach theoretical knowledge and practical experiment separately in the MCU course. In order to solve these common problems, a new teaching method combined theory and practice based on PROTEUS platform is proposed. This new teaching method is constructed by online teaching resource, experimental box, simulation platform and circuit emulator, it is mainly implemented through a specific program. It has proved that this new teaching method not only let students understand the MCU principles well, but also improve their capability to develop a systematic design.
\end{abstract}

Keywords-Microcontroller; Theoretical Teaching; Practical Teaching; PROTEUS Platform;

\section{INTRODUCTION}

Microcontrollers with its high-level performance and reliability are widely used in the field of industrial control, consumed instruments, medical instruments, military and aerospace industry, agriculture and some other applications. At present, many colleges treat the MCU course as an important fundamental curriculum in the major of automation and electronics. The MCU course is a strong practical curriculum and it requests some corresponding experiments after learning some theoretical knowledge. However, the microcontrollers teaching of many colleges always focus on the introduction of principles and ignore the practical parts [1]. Although some colleges have the experimental curriculum, its corresponding practical experiments are relatively simple. Many students who are lack of systematic training do not really know the whole development process about microcontroller application, and they also have not an emotional understanding of the theory about microcontrollers. And someone even does not know how to start when they have a specific program about microcontroller application.

In this paper, PROTEUS platform is introduced to reform the MCU teaching of college. In order to solve the common problems in the MCU course, an idea which treat student as a god and focus on the application capacity about microcontroller of students is proposed, it put forward a new teaching method which is composed of online resources, experimental box, soft simulation platform and circuit emulator. Besides, we also can reform and research on the
MCU books, teaching content, teaching method and assessment method. PROTEUS simulation platform for microcontroller courses largely solves the MCU Course dull ills and reduces the cost of experimental equipment. At the same time, this reform can stimulate the interest, initiative and creativity of student effectively on the design of microcontroller, it also has a great significance to improve the practical ability level and enhance employment competitiveness of students [2].

\section{INTRODUCTION OF PROTEUS PLATFORM}

As an EDA tool, PROTEUS simulation platform which is produced by the Labcenter Electronic is widely used in the word. Compared to other simulation tools, it has the following characteristics [3].

- The PROTEUS platform provides many simulations such as analog circuit simulation, digital circuit simulation, microcontroller simulation and some hardware simulations.

- The PROTEUS platform support many microcontrollers and microprocessors such as 68000 series, 8051 serials, AVR serials, PIC serials, Z80 serials, ARM7 and some other chips. It also can realize the debugging between microcontrollers and PROTEUS simulation platform.

- $\quad$ The PROTEUS platform provides a lot of memory and peripheral chips.

- The simulation analysis of PROTEUS platform is powerful as same as SPICE.

The Fig.1 shows the PROTEUS simulation platform.

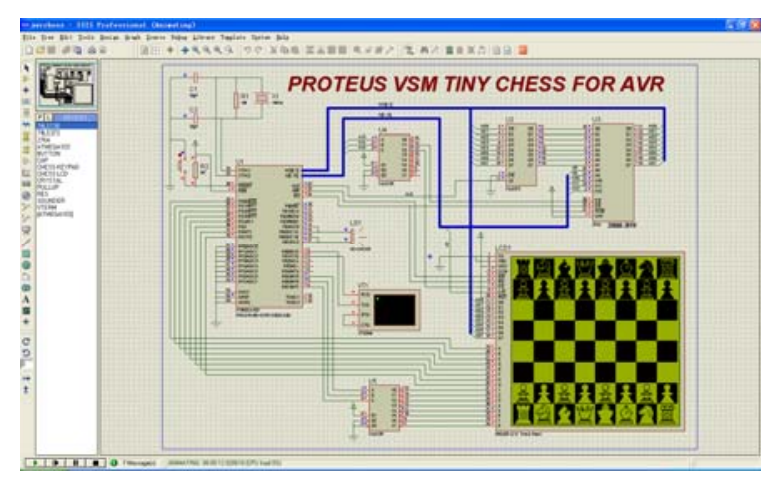

Figure 1. Proteus simulation platform 


\section{MCU TEACHING BASED ON PROTEUS}

\section{A. Disadvantages of Traditional MCU Teaching}

Many universities in china adopt a traditional teaching method which teaching first and then having a corresponding experiment in the MCU course. At present, most traditional microcontroller teaching use the MCS-51 serials as an example to teach, it always introduces the fundamental structure of microcontroller at the beginning of the teaching, and then assembly language syntax, programming and some designs of peripheral interface circuits are introduced in the classroom. When talking about the teaching method, traditional MCU course always combines theoretical teaching with a small amount of practical experiments, and the practical experiments mostly are confirmatory experiments and training experiments. Besides, the hours of theoretical teaching are far more than the practical experiments in most universities. This traditional teaching method has the following disadvantages.

- The traditional teaching always introduce a large amount of principles that make students feel boring especially the programming syntax, and it also difficult for students to understand what they have listened.

- The traditional teaching always focuses on the architecture of microcontroller with a small amount of practical introduction.

- The traditional teaching always introduces hardware and software separately, and it stress seldom that the combination of hardware and software system design, this makes that students are lack of systematic thinking when they build a microcontroller application.

\section{B. Theoretical Teaching Based on PROTEUS Platform}

The teaching of microcontroller course involves both hardware and software knowledge, so we should understand and master the internal structure of microcontroller and the resources of peripheral interface based on the fundamental issue of engineering application in the view of engineers. The following mainly talks about the timer and counter of MCS-51 serials microcontroller which explains the reform and experience of MCU theoretical teachings based on the PROTEUS platform.

The MCS-51 serials provide two 16-bit timer/counters named timer 0 , timer 1 . These two time/counters have four operational mode, they are mode 1 , mode 2 , mode 3 and mode 4 . Timer 0 is composed of the special register TH0 and TL0, Timer 1 is composed of the special register TH1 and TL1. Besides, the timer/counter is also controlled by the timer mode control register (TMOD) and timer control register (TCON). Due to timer 0 and timer 1 operate the same way, the following example mainly talks about timer 0 and it is working in mode 1 [4].

This example requires that a pulse with its cycle is $100 \mathrm{~ms}$ is generated in the P1.0 of microcontroller. At first, the counter initial value $\mathrm{M}$ is calculated by the following formula.

$$
M=2^{16}-t \times \frac{f_{c l k}}{12}
$$

In the formula, $\mathrm{t}$ is the alarm time and $f_{c l k}$ is the frequency of crystal. In order to meet the requirements of design, the $\mathrm{M}$ is calculated as follow.

$$
M=2^{16}-0.05 \times \frac{12 \times 10^{6}}{12}=15536
$$

The initial value $\mathrm{M}$ is transformed to $3 \mathrm{CBOH}$ in hexadecimal form, so the register $\mathrm{THO}$ is $3 \mathrm{CH}$ and the register TLO is $\mathrm{BOH}$. At beginning of the system design, the hardware simulation is designed in the PROTEUS platform. A microcontroller and a virtual oscilloscope are presented in the Fig.2.

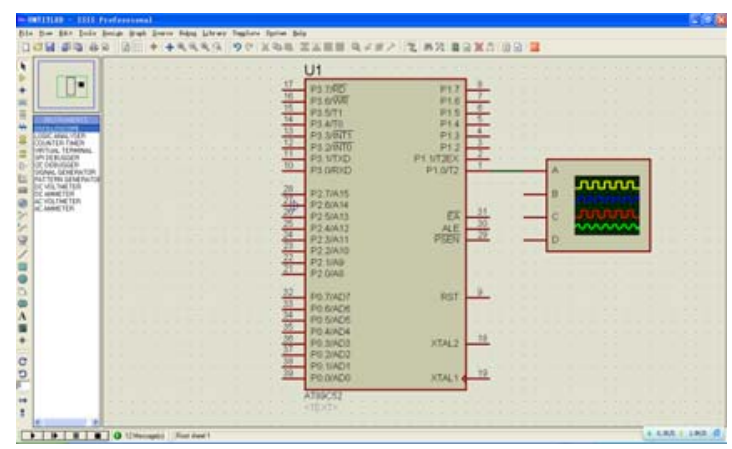

Figure 2. Simulation of Timer/Counter in PROTEUS

The microcontroller needs corresponding source code so that it can operate normally. In the system design, a soft named KEIL is presented and a file with the hexadecimal style what the PROTEUS required is compiled and generated by the KEIL. The source code editing window is shown in Fig.3. In the source code, it mainly adopts the interrupt mode of microcontroller to implement the requirements, the related registers about timer/counter are introduced and initiated first. The register $\mathrm{TH} 0$ and $\mathrm{TLO}$ are $3 \mathrm{CH}$ and $\mathrm{BOH}$, so the time alarmed by the timer is $50 \mathrm{~ms}$. The requirements of the design are implemented by the main function and the interrupt function [5].

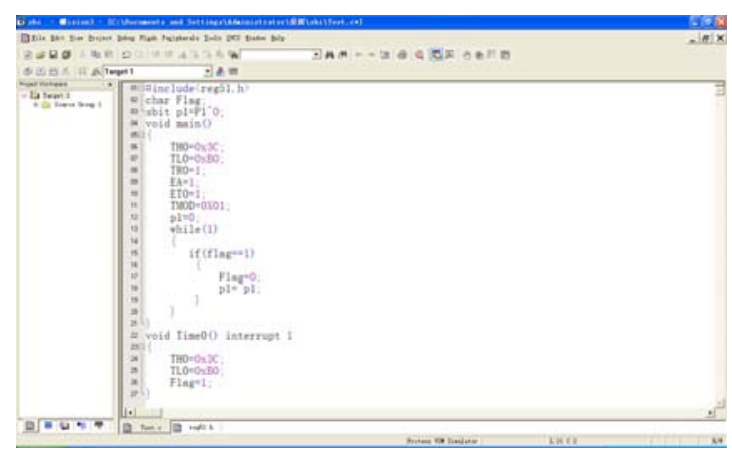

Figure 3. The source code in KEIL 
In the PROTEUS simulation platform, we can download the hexadecimal file from the KEIL into the microcontroller. When the system simulation is working correctly, the oscilloscope will display the result vividly. The output signal of oscilloscope is shown in Fig.4.

As Fig.4 shows, the cycle of the simulation waveform is $100 \mathrm{~ms}$ and its amplitude is $5 \mathrm{~V}$, so the simulation result meets the requirements of the design.

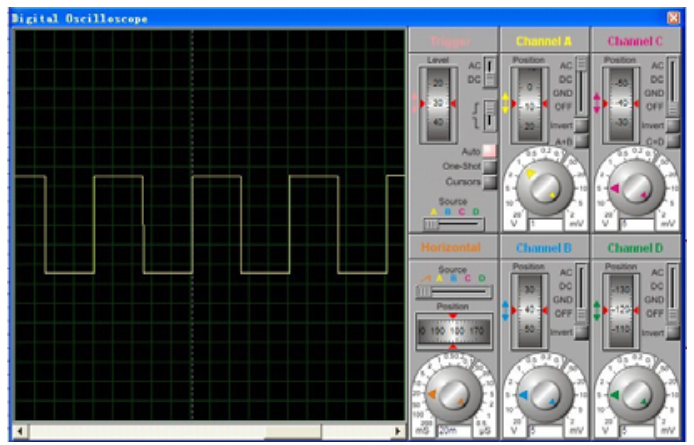

Figure 4. The simulation result in PROTEUS

From the new teaching method above with multimedia equipments in the classroom, students can easily understand and master the design of hardware circuit, language programming and the whole process of a specific program. In the PROTEUS platform, students can modify the circuit and the source code freely until the system meets the requirements of the design. This new teaching method not only improves the emotional acknowledge of students about microcontroller, but also stimulates the interest of students on the MCU course. The reform of MCU course based on PROTEUS platform has following advantages [6,7].

- The new teaching method teaches the theoretical knowledge in the view of engineer and combines hardware circuit design with the programming. It makes students understand theoretical knowledge well and improves the quality of teaching effectively.

- $\quad$ The new teaching method demonstrates the teaching example vividly and the multimedia equipments are convenient for teachers to display what they have taught. Besides, the hardware circuit in the PROTEUS and the programming in the KEIL can be modified quickly so as to understand the book deeply for students.

\section{Practical Teaching Based on PROTEUS Platform}

The practical experiments of microcontroller course are always the validation of theoretical knowledge in the practical teaching. The contents such as programming, usage of I/O port, usage of interrupt and timer/counter, LCD and keyboard using of the experiment are often pre-designed by experimental teachers, most students finish the experimental task only to complete the syllabus. Although this traditional teaching method can help student learn about the development kit of hardware and software and make students familiarize the microcontroller area, it is useless for students to develop the ability of practical application and stimulate the interest in learning and initiative, some students even do not do the preparation before the experiment and copy the procedures or experimental reports from others. Most students think that they can not achieve adequate knowledge from this traditional practical teaching, and it is difficult for them to finish a specific program about microcontroller application $[8,9]$.

In order to solve the problems in the traditional practical teaching, some measures should be taken into account. At first, the experiment instructions only give the requirements and some principle indications of the experiment to students, it requests that students should design the hardware circuit and the procedure independently with the purpose and requirements of the experiment. Students can simulates the circuit what they designed in the PROTEUS platform, and then test the simulation in an experimental box to verify the truth of simulation based on PROTEUS. With the traditional practical teaching, the new teaching method mainly encourages students to design the experiment independently and develops the ability of solving problems. A calculator based on 8051 is introduced to help analysis the reform on practical teaching.

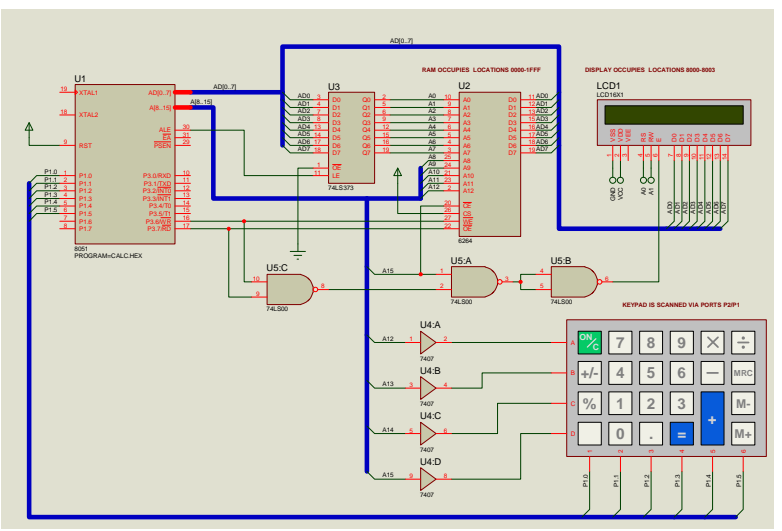

Figure 5. Simulation of calculator based on 8051

As Fig.5 shows, the calculator is composed of a microcontroller, a data latch, a static RAM, a keyboard, a LCD and some other comments, so we should understand the operation principles of them first. The latch is used to latch the data from the shared data bus and address bus. The static RAM provides additional data memory for the microcontroller. The LCD is used to display the result calculated by the processor. With the PROTEUS platform, students can design a systematic program independently and put their ideas into practice. Only in this way can students understand what we have learned effectively.

\section{CONCLUSION}

As an excellent simulation tool, the virtual laboratory based on PROTEUS platform can achieve an effective practical teaching. PROTEUS platform improves the efficiency, quality and flexibility throughout design process of microcontroller-based system, users can shorten the development cycle and obtain huge rewards. The reform on MCU course of college based on PROTEUS platform 
reflects the combination between theoretical teaching and practical teaching, this new teaching method not only can improve the universal problems in the MCU course of colleges, but also can develop the practical ability and innovation ability of students. In this paper, the reform of MCU course mainly aims at improving the quality of theoretical teaching and practical teaching, it enables students to accept more practical training and more comprehensive scientific research.

\section{REFERENCES}

[1] Ying LIU, Fu-Xiang GAO, Xia LI, Reserch on the Teaching Method for Computer Interface Technology Course, 2009 International Forum on Computer Science Technology and Applications, 2009, vol.3, pp.104-106.

[2] Bulent Koc A, Koc Caner, and Vatandas Mustafa, Software tools for teaching microcontroller programming in agriculturalengineering education, American Society of Agricultural and Biological Engineers Annual International Meeting, 2008, vol 7, pp. 4422-4431.

[3] http://www.labcenter.co.uk/.
[4] Yi-Gang ZHANG, Xi-Yuan PENG, Shou-Da JIANG, Li-Yan QIAO, New Design of Microcontroller Apllication based on MCS-51, Harbin Institute of Technology Press, 2003.

[5] Brian W. Kernighan, Dennis M.Ritchie, The C Programming Language, China Machine Press, 2004.

[6] Bo SU, Li WANG, Application of Proteus Virtual System Modelling (VSM) in Teaching of Microcontroller, 2010 International Conference on E-Health Networking, Digital Ecosystems and Technologies.2010, vol.2, pp.375-378.

[7] Ying LIU, Fu-Xiang GAO, Xia LI, Reserch on the Teaching Method for Computer Interface Technology Course, 2009 International Forum on Computer Science Technology and Applications, 2009, vol.3, pp.104-106.

[8] Cika DraZen, Grundler Darko. Proteus Vitual System Modeling used for microcontroller education, 2010 Proceedings of the 33rd International Convention (MIPRO), 2010, pp.1034-1038.

[9] Lin Li-Jun, HU Ning-Ya, Building Virtual laboratory environment for Microcomputer principle \& Interface Technology curriculum, Computer Science and Automation Engineering(CSAE) International conference, 2011, vol.2, pp. 529-532. 